\title{
CULLEN AND THE STUDY OF FEVERS IN BRITAIN, 1760-1820
}

\author{
by
}

W. F. BYNUM*

\section{INTRODUCTION}

THERE IS probably no clinical subject in the whole history of medicine with a more extensive literature than fevers. This is hardly surprising, since acute infectious disorders accounted for so much of the medical experience of earlier generations. At the same time, this vast literature has produced only a few works before the late nineteenth century deemed worthy of inclusion in Garrison and Morton's bibliography of landmarks in the history of medicine: the germ theory of disease has affected both the way we approach these disorders and the value we assign to earlier formulations. Since the temporal limits of the papers in this volume fall well shy of the germ theory, there are no privileged positions: in fact, despite important differences of culture, knowledge, and intent, Hippocrates and William Cullen were part of a common medical tradition.

The British fever literature from about 1760 to 1820 is rich in polemic, insight, and change. But it would be a brave historian indeed who would claim to discover a progressive thread. Rather; the threads seem naturally to lead outward into the medicine and culture of the period instead of forward to the theories and science of later decades. In what follows I shall thus be concerned with briefly outlining some of the themes in the literature which strike me as significant to those who were alive at the time. I shall use William Cullen as my reference point, partly because of his position within the medical world of Enlightenment Britain, and partly because his work contains a full discussion of fevers embodied in a series of writings covering virtually the whole of medicine. I shall suggest, however, that Cullen's ideas were never accorded full assent by his peers, nor would they have been expected to, given the extent of individualism in late eighteenth- and early nineteenth-century medical Britain.

\section{CULLEN ON FEVERS}

The place of William Cullen (1710-1790) in the history of medicine is not easy to assess. The impact of his teaching and writing is not always so clearly evident as that of Herman Boerhaave, with whom he seems to invite comparison. There are indeed some striking parallels between them: in their early contributions to, and continuing interest in, chemistry; in the breadth and eclecticism of their medical writings; in the

*William F. Bynum, M.D., Ph.D., Wellcome Institute for the History of Medicine, 183 Euston Road, London NW1 2BP. 
shape imposed on these writings by the practical exigencies of teaching; in the genuine affection accorded them by their pupils. Cullen was, of course, half a century younger than Boerhaave, and the student body in Enlightenment Glasgow and Edinburgh was never so international as in Boerhaave's Leyden. Cullen always lectured in English and while Latin editions and European-language translations of his works assured him of a wide readership, Cullen's career and writings seem more explicitly related to British debates and medical styles than do Boerhaave's to Holland. ${ }^{1}$

At various stages in his long academic career (Glasgow, 1744-55; Edinburgh, 1755-89) Cullen occupied chairs which left him with responsibilities for medical subjects of scientific, theoretical,. and practical import: chemistry, physiology, materia medica, clinical medicine. His publications reflected these lecturing duties, sometimes appearing from student notes without his permission. His Institutions of medicine (1772) were largely physiological but were closely related to his most famous work, First lines of the practice of physic (4 vols, 1776-1784). This expounded the theory, diagnosis, and treatment of diseases, which were in turn arranged along the nosological categories Cullen had outlined in 1769, in his Synopsis nosologiae methodicae.

We have no comprehensive modern study of the development of Cullen's medical ideas, but he does not appear to have undergone any major conceptual upheavals during his long career. Rather, much of the edifice seems to have been worked out by the time he moved from Glasgow to Edinburgh, although his principal publications were then still before him. Despite the formal quality to much of his writing, he was not excessively doctrinaire. His pages are crammed with facts, observations, and qualifications, and it is significant that Cullen's nineteenth-century biographer John Thomson could so often cite instances where Cullen himself had anticipated criticism subsequently levelled at his work. ${ }^{2}$ David Hume's friendship and philosophical influence undoubtedly neutralized some of the dogmatism to which Cullen might have been tempted by his powerful academic position. Cullen was no full-blown Humean sceptic, but his own discussions of causation in medicine were clearly composed by one who had absorbed the gist of Hume's philosophical message. ${ }^{3}$ Further, Cullen apparently was not bothered by two divergent tendencies in his medical thought: his groping towards synthetic physiological and patho-physiological laws (à la Newton), on the one hand, and towards the analytic implications of nosological categories on the other. Cullen's discussion of fevers exemplifies some of these competing tendencies. Within his nosological schemes, fevers occupy a definite place, as an order

\footnotetext{
${ }^{1}$ In general, cf. Lester King, The medical world of the eighteenth century, University of Chicago Press, 1958; G. A. Lindeboom, Herman Boerhaave, London, Methuen, 1968; A. L. Donovan, Philosophical chemistry in the Scottish Enlightenment, Edinburgh University Press, 1975; W. F. Bynum, 'Health, disease, and medical care', in G. S. Rousseau and Roy Porter (editors), The ferment of knowledge, Cambridge University Press, 1980, pp. 211-254.

2 John Thomson, An account of the life, lectures, and writings of William Cullen, 2 vols., Edinburgh, Blackwood, 1859.

${ }^{3}$ C. J. Lawrence, 'Early Edinburgh medicine: theory and practice', in R. G. W. Anderson and A. D. C. Simpson (editors), The early years of the Edinburgh Medical School, Edinburgh, Royal Scottish Museum, 1976, pp. 81-94; idem, 'The nervous system and society in the Scottish Enlightenment', in B. Barnes and S. Shapin (editors), Natural order, London, Sage, 1979, pp. 19-40.
} 
Cullen and the study of fevers in Britain, 1760-1820

of one of the four classes of disease which he delineated, schematically shown as follows:

Classes

$$
\text { Pyrexiae }
$$

Fevers

Inflammations

Eruptions

Haemorrhages

Fluxes

(2)

Neuroses

Comata

Adynamiae

Spasmodic affections

Vesaniae

(3)

Cachexia

(4)

Locales
Emaciations

Swellings

Impetigines

[Various]
(Examples)

("typhus" intermittent fever)

(hepatitis, pleuritis)

(smallpox, plague)

(consumption, haematuria)

(dysentery)

(apoplexy)

(syncope, hypochondriasis)

(epilepsy, whooping-cough)

(mania, melancholia)

(dropsy)

(scurvy, syphilis)

Several general comments on this classification are in order before we look at the way Cullen handled fevers. It possesses many of the familiar eighteenth-century features of the symptom-based nosology. Thus, epilepsy and whooping-cough share spasmodic qualities, and the praeternatural expelling of blood links consumption and haematuria. But Cullen was aware that he had distanced himself from earlier symptom-based nosologists like Sauvages, and he was fully sensible both of the contingencies of his own nosological scheme and of the importance of local pathological changes even in diseases which he continued to count as general affections: "It is, I think, now agreed, that the dissection of morbid bodies is one of the best means of improving us in the distinction of diseases ... it is evident that dissection, by showing the parts singly or joinily affected, shows the real and steady changes in the system, upon which the external symptoms depend." $O$ On the other hand, he cautioned against creating nosological categories for diseases without external marks or symptoms. Nosologies were to be based on observation not inference, and the inclusion of silent internal lesions into the scheme introduced another source of error. ${ }^{5}$ Finally, he recognized that the class Locales was an unsatisfactory rag-bag of disorders. Cullen's was, in brief, a pedagogical and heuristic rather than an essentialist nosology, a clinical guide rather than a theoretical system. Accordingly, he did not seem to be disturbed by the discordance between the discrete tidiness of his classes and orders and the more unifying aspects of his pathophysiological theories. His class Neuroses is a case in point. As is well known, Cullen replaced the Boerhaavian emphasis on the blood vessels and their contents as the major source of disease with a patho-physiology in which the nervous system was concert-master. Hoffmann, Gaubius, Haller, Whytt, and others helped shape this part of Cullen's thought and it would be gratuitous to

$4 J$. Thomson (editor), William Cullen, Works, 2 vols., Edinburgh, Blackwood, 1827, vol. 1, p. 423.

s Ibid., vol. 1, p. 461 . 


\section{W. F. Bynum}

claim too much originality for him here. But such was the emphasis which he placed on the nervous system that, at one level, almost all diseases were neurotic (as he defined it), viz. affecting the functions of the nervous system.

Certainly the pyrexias were neurotic. Their distinguishing features consisted of the following: "After the beginning with some degree of cold shivering, they shew some increase of heat, and an increased frequency of pulse, with the interruption of strength in the animal functions."' All pyrexias show these characteristics, the order fever being to a certain extent a diagnosis of exclusion, for fevers, unlike inflammations or haemorrhages, lack any primary or essential topical component. At first glance, it appears that Cullen related the nervous system only through some incidental diminution of the animal functions. In fact, he insisted that the initial stage of cold shivering was caused by a "debility of the nervous power", which consistently "lays the foundation of all the other phenomena". Fever thus in his view consisted of three essential stages: debility, chill, and heat, the first stage being in some sense the cause of the subsequent events. These stages defined fever as a disease in itself, although they were also found in conjunction with other disorders, in which case fever could be identified as a symptom of some more basic process.

In consequence, fever is a disease to be diagnosed by quizzing the patient about his feelings; by observing him for indications of shivering, sweating, and other manifestations of temperature change; and by carefully noting the sequence in which these events occur. Even though Cullen retained the classical distinction of excess heat as one of the defining characteristics of fever, he was unimpressed with the advantages offered by the thermometer as an aid to diagnosis. References to the thermometer are common enough in eighteenth-century discussions of fever, but Cullen and most of his contemporaries mentioned the instrument only to dismiss it. This was partly because variations in body temperature were only part of the entity which they called "fever", but also because these variations, as experienced by the patient, did not correlate very well with the number registered on the thermometer. A patient could report a chill while shivering under the bed-clothes, and yet his temperature as indicated on the thermometer might range from several degrees below to several degrees above "normal". Eighteenth-century thermometers apparently registered a degree or two lower than modern ones, and the frequent reports of patients with temperatures of $94^{\circ} \mathrm{F}$. raise some doubt about their accuracy, but I think that the reasons why Enlightenment doctors used thermometers so little were largely conceptual rather than technological. One of Cullen's younger contemporaries, George Fordyce, went to some pains to demonstrate that marked changes in the patient's sensations during a fever attack were not accurately correlated with results obtained by thermometers. He attributed these discrepancies to lags between the production and dissipation of heat by the body, but it is clear that he trusted the patient more than the thermometer. The essence of fever remaining unknown, it was to be diagnosed by the symptoms it produced and by its external signs. ${ }^{7}$

'Ibid., p. 479.

${ }^{7}$ George Fordyce, $A$ dissertation on simple fevers, London, J. Johnson, 1794, pp. 8ff, 102ff.; cf. Samuel Davidson, The history of medicine, Newcastle, S. Hodgson, 1794, p. 34; James Currie, Medical reports on the effects of water, 2 vols., Liverpool, J. M'Creery, 1804. 


\section{Cullen and the study of fevers in Britain, 1760-1820}

Cullen's own description of the fundamental characteristics of fever's pathophysiological manifestations owed much to Hoffmann; some to Hippocrates, Sydenham, Gaubius, and other authors; and virtually nothing to Boerhaave, whose basic theories he rejected. Cullen deemed these characteristics more or less constant in the fever paroxysm itself, but the paroxysms possessed their own patterns over time which gave the fevers their generic names: continued, synchochic (a relatively rare continual form), "typhus", remittent, intermittent, etc. Cullen's vocabulary was thoroughly traditional at this point; in practice he made the sharpest distinction between continued and intermittent fevers, even while insisting on a periodicity to all fevers.

But the relatively precise entity of the fever paroxysm became much more contingent and conceptually ambiguous when Cullen turned to causes and treatments. Causes could be proximate and remote; external and internal; predisposing and exciting. Fevers could be "caused" by a variety of factors: miasmata, contagion, heat, cold, venery, fear, dirt, putrefaction, or bad air. His discussions were logical to the extent that he related these factors directly or indirectly to the physiological events of fever, but his categories were frequently elastic. Cold, for instance, was in different circumstances regarded as a stimulant or a depressant; a cause of fever, a stage in its evolution, or a legitimate part of its cure. Moderate cold was bracing and stimulating and hence could combat both the debility and heat of fever. Intense cold was debilitating in itself and this was the reason why prolonged exposure to cold not infrequently preceded the onset of a fever. We can see here the kind of reasoning which was to produce the schematic representation of health and disease so beloved by late eighteenth-century doctors, whereby extremes were conceived as being closely related. For instance, John Brown saw prolonged stimulation as leading ultimately to debility. It is also significant that Cullen, from whose work Brown, Rush, and other apostles of the schematization of disease derived their own symptoms, never succumbed to the indulgence himself. Cullen was far too anxious to convey a sense of the complexities of diseases and to take account of a vast array of observations connected with their aetiology, natural history, and treatment. ${ }^{8}$

Thus, despite his emphasis on the role of debility in the natural history of fever, Cullen's therapeutic recommendations were never so simple as those of Brown, who stimulated, or Rush, who depleted. The treatment of fever was complicated and must be related not only to the different stages of the fever paroxysm but to the identified causes of the complaint and to the peculiarities of the patient's constitution, temperament, and mode of life. Although stimulant therapy - wine, opium, tonics, cinchona bark - occupied a central position, as befitted the nature of the disorder, many other therapeutic procedures and medical preparations had their places in Cullen's fever armamentarium. He cautioned against excessive and indiscriminate bloodletting in fevers, but this and other antiphlogistic remedies had, he felt, their circumscribed uses: in warm climates, in particular varieties of fever, in certain kinds of patients, or at some stages of the illness. Cullen never erected a set of definitive therapeutic instruc-

'See, for instance, R. H. Shryock, The development of modern medicine, London, Gollancz, 1948. 


\section{W. F. Bynum}

tions which were to be applicable in all circumstances.9 This is why, unlike John Brown, who had disciples rather than pupils, Cullen had only pupils.

On the other hand, Cullen had relatively limited confidence in the healing power of nature and thus remained rather energetic therapeutically. Much of the fever literature from the Hippocratic writings to the Enlightenment (and beyond) was predicated on the assumption that many fever symptoms stemmed from the body's inherent capacity to restore a healthy equilibrium. Thus, sweating, vomiting, diarrhoea, etc., could be viewed as the body's attempt to rid itself of some morbific matter or to correct a humoral imbalance; the doctor took his cue from nature with what could be called supportive therapy. To Cullen, however, only the initial reactive or spasm phase of the fever paroxysm was part of the vis medicatrix naturae, and even this had to be countered medically in most instances, for the spasm quickly led to a depletion of nervous energy, causing debility. ${ }^{10}$

Several salient features emerge from this brief discussion of Cullen's views on the causes, consequences, and therapy of fevers. Causation was complex and variable, ranging from environmental factors through personal habits to specific contagia. Cullen believed that specific contagia were more commonly found in the exanthemata such as smallpox and measles, but that the disease he called typhus was also frequently caused by a specific contagion. His classification of fevers, however, was not based on aetiology but on clinical course and while his nosological table suggests that the differences between, for instance, a typhus and a remittent fever are generic in nature, in practice he admitted that sharp divisions are difficult to determine and fevers may change from one kind to another. Fevers may have local pathological manifestations, but these are not primary. Consequently, the diagnosis of fever is implicitly one of exclusion, since the general symptoms of pyrexia combined with significant localizing symptoms generally put the disease into another order such as the fluxes or exanthemata. Finally, despite the contingencies of the clinical course, debility dominated an attack of fever and therefore therapy in general must be supportive and stimulant rather than antiphlogistic and depletive.

These were the main ramifications of Cullen's theories of fever. How did they relate to wider debates on fever during the period of their currency?

\section{THE WIDER DEBATES, $1760-1820$}

\section{A. The geography of fevers}

The study of the geography of disease has a long and honourable history: eighteenth-century doctors found sterling examples in the Hippocratic Corpus and, more immediately, Sydenham's investigations of the diseases of London. ${ }^{11}$ Of all

\footnotetext{
${ }^{9}$ Cullen, Works, op. cit., note 4 above, vol. 1, pp. 650-652, where the mere outline of his therapeutic recommendations takes more than two pages.

${ }^{10}$ Max Neuburger. The doctrine of the healing power of nature throughout the course of time, trans. L. S. Boyd, [New York, n.p. 1943].

"C. J. Glacken, Traces on the Rhodian Shore, Berkeley, University of California Press, 1967. For a study of late eighteenth-century French ideas of medical geography and nosology, cf. J.-P. Peter. 'Disease and the sick at the end of the eighteenth century'. in R. Forster and O. Ranum (editors), Biology of man in history, Baltimore, Md., and London. Johns Hopkins University Press, 1975.
} 
diseases, fevers were the ones most obviously related to the variables of geography and climate, and the constant expansion of the British Empire with the establishment of regular trading routes to India, the East and West Indies, the North American mainland, and parts of the African coast, together with the supporting military and civilian establishments, intensified the impact of fevers on the British consciousness. Studies by Mathias, Tröhler, and others have alerted us to the importance of the military medical services as a source of medical innovation, and it is indeed striking how much of the fever literature of the second half of the eighteenth century was produced by men with practical experience abroad. ${ }^{12}$ The work of James Lind (1716-1794) and Sir John Pringle (1707-1782) is well known, but it is sometimes forgotten that Cullen himself spent several years in Jamaica early in his career, and doctors like George Cleghorn (1716-1789), John Clark (1744-1805), John Coakley Lettsom (1744-1815), and Robert Robertson (1742-1829) guaranteed that debates about the nature and treatment of fevers included more than simply those indigenous to Britain.

Like Cullen, most of these men were Scottish-born or -educated dissenters, barred from the inner circles of medical power in London. Neither Lind, physician to Haslar, nor Robertson, physician to Greenwich, became Fellows of the College of Physicians. Lettsom busied himself in medical practice, philanthropy, and the founding of dispensaries and societies, but was never a physician to one of the major London hospitals. ${ }^{13}$ Cleghorn, author of a much-admired work on the diseases of Minorca, spent his civilian years in Dublin lecturing in anatomy. ${ }^{14}$ Clark left the East India Company for Newcastle. Only Pringle managed to scale the highest barriers and achieve Fellowship in the College and Presidency of the Royal Society. Like many energetic men denied the fullest rewards of the social system, they were concerned with changing its ground rules. Army, navy, and civilian maritime experience of necessity brought them face to face with the devastating consesquences of fevers among groups in confined spaces and in alien climates: "The millions who perish in the fleets and armies of contending nations, are swept away in greater multitudes by the secret malignancy of [febrile infection], than by all the destructive implements of war."1s Robertson's sentiment was urged time and again to military authorities, together with many of the utilitarian and economic arguments which Edwin Chadwick was much later to elucidate in the civilian context. Margaret Pelling was correct to stress that fever rather than cholera was the real driving force behind public health policies developed in Victorian Britain, and many of the ideas and some of the policies were generated in the Enlightenment military services. ${ }^{16}$

The enlarged geographical sensitivity which practice in warmer climates left Lind,

\footnotetext{
${ }^{12}$ Peter Mathias, 'Swords and ploughshares: the armed forces, medicine, and public health in the late eighteenth century', in J. M. Winter (editor), War and economic development, Cambridge University Press, 1975; U. Tröhler, 'Quantification in British medicine and surgery, 1750-1830, with special reference to its introduction into therapeutics', Ph.D. thesis, University of London, 1978.

${ }^{13}$ T. J. Pettigrew, Memoirs of the life and writings of the late John Coakley Lettsom, 3 vols., London, Longman, 1817; J. C. Lettsom, Reflections on the general treatment and cure of fevers, London, Cornish, 1772.

${ }_{14}$ George Cleghorn, Observations on the epidemical diseases in Minorca, London, D. Wilson, 1751.

13 Robert Robertson, An essay on fevers, London, [The Author], 1790.

${ }^{16}$ Margaret Pelling, Cholera, fever and English Medicine, 1825-1865, Oxford University Press, 1978.
} 
Pringle, Robertson, and many others with manifested itself in several ways. In the first place, they used the concepts of miasmata and contagion not as alternative but complementary explanatory entities. Lind's Essay on diseases incidental to Europeans in hot climates (1768), the first work of its kind in English for seventy years, attempted to relate the fevers, dysenteries, and other acute diseases prevalent in Africa, India, and the West Indies to the peculiar environmental conditions found there. Permutations in the temperature and characteristics of the air seemed especially pertinent in the causation of these diseases, an observation which was reinforced by Lind's treatment of sailors with fevers caught in the confined spaces below deck. Fresh air could be protective, not only in the macroscopic case of miasmatic marsh vapours but also in the microscopic instance of the contagion spread from person to person. ${ }^{17}$

Coupled with this dogged obsession with fresh air was a new, urgent plea for personal cleanliness. Both Lind and Pringle fought for an increase of soap allowances, and for the regular washing of clothes and bodies among His Majesty's troops. It is hard for us to appreciate that, within the eighteenth-century context, these were not necessarily common-sensical activities. Cleanliness is in the eye of the beholder, but it seems certain that, from about the 1750s, a new medical perception of dirt emerged. Temkin has linked it to the association of cleanliness and moral worth by dissenting Protestants, especially Methodists, whose founder John Wesley preached that "Cleanliness is next to Godliness". ${ }^{18}$ These disciples of cleanliness probably did come to preach this gospel for symbolic as well as practical reasons, but in the case of military doctors like Lind and Pringle their remarks on cleanliness and personal hygiene were embedded in their general observations about the environment background to disease.

Despite the appalling mortalities of Europeans on board ship and in warm climates, Lind was far from despairing that the equatorial latitudes were of necessity a white man's grave. He held that race was a relatively superficial matter - only skin deep caused by climatic conditions. He expected acclimatization to occur relatively rapidly, at which point Europeans would be no more vulnerable to tropical fevers than were those indigeneous to these areas. Nineteenth-century commentators on these matters were frequently less sanguine, partly because their notions of race had hardened into a much more deterministic, hereditarian mould, but also because further experience with the realities of tropical conditions had convinced them that many tropical diseases were qualitatively different from those found in Europe. ${ }^{19}$

Medical environmentalism was certainly not unique to Enlightenment doctors, but this environmentalism enabled them to assimilate a whole variety of acute disorders into traditional explanatory frameworks. ${ }^{20}$ Lind, Pringle, Robertson, and others

\footnotetext{
17 James Lind, Essay on diseases incidental to Europeans in hot climates, London, T. Becket, 1768; idem, Two papers on fevers and infections, London, D. Wilson, 1763.

18 Owsei Temkin, 'An historical analysis of the concept of infection', in The double face of Janus and other essays in the history of medicine, Baltimore, Md., and London, Johns Hopkins University Press, 1977.

19 Philip Curtin, The image of Africa, London, Macmillan, 1965.

${ }^{20} \mathrm{~L}$. J. Jordanova, 'Earth science and environmental medicine: the synthesis of the late Enlightenment', in L. J. Jordanova and R. S. Porter (editors), Images of the earth, Chalfont St. Giles, British Society for the History of Science, 1979, pp. 119-146.
} 


\section{Cullen and the study of fevers in Britain, 1760-1820}

modified Cullen's emphases at various points, but Cullen himself identified roughly the same list of broad environmental categories which were observationally implicated in the aetiology of fevers.

\section{B. The critique of nosology}

I have already suggested that Cullen must be seen as a contingent, rather tentative nosologist, even though he insisted that diseases are real and therefore the names which he gave to them have more than mere arbitrary significance. He was without doubt the most influential nosologist in Britain - far more so than men like Thomas Young and John Mason Good who attempted to improve on Cullen's classifications. ${ }^{21}$ His division of disease into four major classes found most assent. Given the nature of eighteenth-century medical knowledge, it was probably inevitable that his further subdivisions would be subjected to a considerable amount of modification and individual criticism. Indeed, Cullen himself often publicly admitted his own uncertainties.

In the case of the pyrexias, these criticisms stemmed from two principal sources: on the one hand, from the Brunonians, and on the other, from those like Robert Robertson and John Clark who carried the environmental analysis of fever beyond Cullen. Both groups emphasized the essential unity of all fevers, the one group from physiological, the other from therapeutic principles.

Brown and his disciples were simply not very concerned with nosology in its traditional form. Brown's simple division of all diseases into either sthenic or asthenic types was based on his theory of a characteristic property of living things which he called excitability, excess or deficiency of which produced one of the two types. He set aetiological and nosological considerations aside in favour of the observed consequences of disease and their correction by therapy. Brown believed that most diseases ultimately produce debility, or asthenic disorders, either directly or indirectly, through the exhaustion of this principle of excitability. Consequently, most diseases had to be treated by stimulants, of which spirits, wine, and opium were deemed the most useful by Brown and most of his followers.

There were some nuances to Brown's system, although, as Samuel Davidson remarked, were Brown correct, the art of medicine "could be acquired in six minutes". ${ }^{22}$ Nevertheless, one can see that Brown's consideration of fevers and other diseases through their physiological modifications was essentially following the Cullenian tradition, even if his teacher was a far more subtle observer. But Francis Riollay (d. 1797) independently recognized the disjunction between theory and practice inherent in late eighteenth-century formulations of fever. How, he asked, could nosology be a useful enterprise when the proposed causes of fevers were so multifarious and problematic? The same "cause" - cold, fever, miasma, etc. - could purportedly produce generically different fevers, an assertion which made nonsense of the belief that nature is constant in her operations. Rather, he insisted that "fever is no disease in itself; that in all cases, it is symptomatic of some affection; and that it is

\footnotetext{
${ }^{21}$ King, op. cit., note 1 above; Knud Faber, Nosography, the evolution of clinical medicine in modern times, New York, Paul Hoeber, 1930.

22 Davidson, op. cit., note 7 above, p. xx.
} 


\section{W. F. Bynum}

never primary or essential. Where the disturbance of functions points out the seat of the disorder, fever is unanimously called symptomatic; but if the seat affected is not obvious to the senses, it is reckoned essential: whereas, it is more natural to think, that as in many cases fever is a symptom of a particular affection, it also is a symptom when the affection is general. Fever seems to be Nature's common signal of distress. "23 This remarkably modern formulation of the fever problem seems to have fallen on barren soil, even though it was delivered in a Gulstonian Lecture before the College of Physicians. Nevertheless, Riollay recognized that excessive preoccupation with the nosology of fevers was leading doctors away from the more difficult task of understanding these disorders in terms of their external causes. Only then could a consistent nosology be produced.

Riollay's avowed motive was the unification of theory with practice. Robert Robertson, John Clark, John Millar, and other empirically-minded doctors wanted to rid medicine of pernicious and obscure theories in favour of a medicine which was grounded in the practical realities of the bedside. They had read their Sydenham but believed his influence to have been ambiguous, for he was the source of the modern tendency to multiply disease categories fruitlessly: "Even Sydenham, a favourite author, I observed, went on adding annually new [genera and species of fever] to the immense stock." 24 Robertson's own experience in more than thirty years' service in the Royal Navy had convinced him that fever is always infectious, and is always the same essential disease. Its different varieties result from the considerable number of environmental causes, but once a fever is contracted it becomes infectious. Further, even smallpox and plague are not substantially different from the disorders commonly called typhus, nervous, or intermittent fevers. John Clark reinforced this stance: "I am fully convinced that although many varieties [of fever] happen according to constitution, season, situational climate: yet everywhere fever is essentially the same, or, in other words, consists only of one Genus; and that the only species which can be well ascertained, are the following, viz. Intermittent, Remittent, and Continual Fevers."2s The division was of convenience only, since Clark held that species can mutate from one form to another.

These nosological critiques were advanced as part of a Baconian programme for the reform of medicine. Robertson had no doubt that naked empiricism could substantiate the essential unity and infectious nature of all fevers. Tröhler has shown how this programme relied on the tabular reporting of multiple cases. This procedure was to guarantee objectivity and was to be coupled with the rigorous recording of therapeutic failure as well as success, an activity which convinced Robertson that he had the data with which to demonstrate that much traditional fever therapy had been misconceived. ${ }^{26}$

\section{The doctrine of debility and the treatment of fevers}

One consequence of the late eighteenth-century conceptualization of fever as a

\footnotetext{
${ }^{23}$ Francis Riollay. Critical introduction to the study of fevers. London. T. Cadell. 1788.

${ }^{24}$ Robertson, op. cit., note 15 above.

${ }^{25}$ John Clark, Ohservations on fevers. London. T. Cadell, 1780, p. 6.

${ }^{26}$ The fullest discussion of this point is in Tröhler, op. cit., note 12 above.
} 
general disorder was the basic demarcation of fever and inflammation. Cullen spoke occasionally of an inflammatory fever, but many doctors of his generation doubted that the concept was useful, since inflammation could be seen as always a local phenomenon and consequently excluded from the more general disease of fever. The time-honoured treatment of inflammation was, of course, bloodletting and other antiphlogistic remedies. ${ }^{27}$ But the separation of inflammation from fevers meant that the proper therapy of the latter was open to debate.

We have seen how Cullen's own therapeutic recommendations were exceptionally complex, although his doctrine of debility in fever tended to shift the emphasis away from depletive, and towards stimulative, remedies. The shift of opinion between the 1750s and the 1770s can be shown by noting that John Huxham's Essay on fevers (1750) had taken as unproblematic the idea of the general inflammatory fever, the rapid pulse being assumed the result of an increased quantity and velocity of the blood. According to Huxham (1692-1768), bloodletting was almost always called for in fever, to reduce the heat and velocity of the blood and to allow for the absorption of diluting liquids into the bloodstream. ${ }^{28}$

Lind, Clark, Robertson, and other colleagues were much more dubious about the value of bloodletting in fevers. Lind stressed that the "operation is in general to be used with great caution ... in [hot] climates";29 Clark objected to the very phrase "inflammatory fever", since "it leads to bleeding and evacuations" ${ }^{30}$ Robertson polemicized against bloodletting and all debilitating remedies as pernicious to the possible recovery of the patient, insisting that stimulating substances like wine, opium, and, above all, Peruvian bark were indicated in fevers.

There was never complete unanimity on the subject, but the stimulant regimen for fevers came to dominate the British medical scene during the last third of the eighteenth century. Robertson was so convinced of the efficacy of the bark in fevers that he dipped into his own pocket to purchase supplies which he could not obtain through ordinary naval channels. Used early and appropriately, it would cure fever in all climates and conditions, not in the old sense of a specific remedy, but because its physiological actions were precisely those which were required. ${ }^{31}$ So physiological were their conceptions of disease that many late eighteenth-century doctors were suspicious of the idea of the specific medicament and limited use of the word specific to medicines deemed more infallible than others in particular circumstances. ${ }^{32}$

There are similarities between the therapeutic recommendations of the Brunonians and Robertson, Millar, Clark, and their colleagues with naval and tropical experience.

\footnotetext{
${ }^{27}$ For some aspects of the earlier history of the concept of inflammation, cf. Peter H. Niebyl, 'Venesection and the concept of the foreign body', Ph.D. thesis, Yale University, 1969. Its nineteenth-century history is treated in L. J. Rather, Addison and the white corpuscles, London, Wellcome Institute, 1972.

28 John Huxham, Works, 2 vols., London, W. Best, 1788, vol. 2, pp. 10ff; and the essay by D. C. Smith in this volume.

${ }^{29}$ Lind, op. cit., note 17 above, p. 232.

${ }^{30}$ Clark, op. cit., note 25 above, p. 13.

${ }^{31}$ For some typical late eighteenth-century comments on the non-specificity of medical remedies, cf. John Jones, Medical, philosophical and vulgar errors of various kinds. considered and refuted, London,. T. Cadell, 1797, pp. $135 f$.

${ }^{32} \mathrm{Cf}$. Robert Morris and James Kendrick, Edinburgh medical and physical dictionary, 2 vols., Edinburgh, Bell \& Bradfute, 1807, Art: 'Specifics'.
} 
However, there is no evidence of mutual influence, and certainly Robertson and the others made much more extensive use of the concept of infection than did the Brunonians. It is tempting to speculate that occasional successes using the bark in cases of malaria coloured some of these broader generalizations about fever. Certainly doctors whose practices were confined to Britain were generally less enthusiastic about the therapeutic properties of cinchona bark than were Robertson and Millar.

Robertson did not die till 1828 , by which time he had seen the notion of the infectious fever established as part of the rationale behind a series of fever wards and hospitals in many parts of the British Isles. There was much personal and professional interchange between the exponents of the military hygiene movement and the early advocates of fever hospitals. Clark himself was instrumental in the establishment of the fever hospital in Newcastle; and Haygarth in Chester, Percival and Ferriar in Manchester, Currie in Liverpool, Stokes in Dublin, and Bateman and Armstrong in London shared many common attitudes towards the nature, prevention, and treatment of fevers. I have elsewhere examined some aspects of this fever hospital movement and will not go into any detail here. ${ }^{33}$ But two or three points seem pertinent to understanding the early nineteenth-century fever literature. First, the use of cinchona bark in fever never became as firmly established in the British-based doctor as it did with his colleagues with overseas experience. Stoker rarely found it useful in the Irish setting, and Bateman deplored the way in which the bark's association with wine had led to its widespread use in domestic fevers. These later physicians continued to use the vocabulary of debility, but their methods of combating it changed. Particularly popular with the early fever hospital physicians was James Hamilton's work on the value of gentle purging in fevers, a treatment which Hamilton insisted (contrary to traditional belief) actually stimulated the patient and hence was appropriate in diseases of debility. ${ }^{34}$ Second, doctors by the 1810 s were once again prepared to accept the notion of the inflammatory fever, sometimes local in its manifestations but often of a more general nature. In 1818 Thomas Bateman (1778-1821), physician to the London Fever Hospital, recounted how, as a young physician in the late 1790s, he had employed the then fashionable method of treating fevers, bark. ${ }^{35}$ Twenty years later he had abandoned this fashion of his youth and turned to bloodletting and other antiphlogistic remedies to relieve the inflammatory symptoms of fever. At about the same time, Henry Clutterbuck attempted to reconcile the general symptoms of fever with the more precise notions of local pathology by advancing the theory that brain inflammation lies behind all fevers. (In France, Broussais located the seat of all mankind's afflictions in gastro-intestinal inflammation: it was, he wrote, "the destiny of the stomach always to be irritated". ${ }^{36}$ Niebyl has called this reversion to more

${ }^{33}$ W. F. Bynum, 'Hospital, disease and community: the London Fever Hospital, 1801-1850', in Charles Rosenberg (editor), Healing and history, New York and London, Science History Publications and Dawson's, 1979, pp. 97-115.

34 James Hamilton, Observations on the utility and administration of purgative medicines, 4th ed., Edinburgh, Constable, 1811 , p. 25.

${ }^{3 s}$ Thomas Bateman, $A$ succinct account of the contagious fever in this country, London, Longman, 1818 , pp. 89ff.

${ }^{36}$ E. H. Ackerknecht, Medicine at the Paris Hospital 1794-1848, Baltimore, Md., Johns Hopkins Press, 1967, chapter 6. 
traditional antiphlogistic remedies in the treatment of fevers a "bloodletting revolution", 37 and it dominated medical opinion in Britain until mid-century. Bloodletting and kindred therapies were justified by appeal to the same principles of empiricism which Robertson and Millar had used to advocate the stimulative properties of bark. The later doctors like Clutterbuck were also practitioners of careful physical diagnosis, routine post-mortem examinations, and the other trappings of "modern" hospital medicine: yet they advocated therapies for fevers which Huxham (or Hippocrates) would have appreciated.

Therapeutically then, the Cullenian era of fevers barely survived his death, although the concept of debility was germane for debates about fever throughout the first half of the nineteenth century. Cullen had always been ambiguous, for unlike Brown, who taught that a fever was invariably debilitating throughout its course, Cullen applied the notion of debility to only a part of the fever paroxysm. Consequently, later authors could still admire Cullen's descriptions of fever, while working out their own therapeutic modalities.

\section{CONCLUSION}

The third section of this paper contains more assertion than evidence, and any of the themes touched on there would bear examination in much greater detail. Such an examination would qualify but not, I believe, substantially alter the basic outlines I have suggested for the British fever debates during the late eighteenth and early nineteenth centuries. I have deliberately kept the story focused on fever, but the relatively specialized literature offers a perspective on the more general question of therapeutic fashion. We have seen that the traditional antiphlogistic regime for fevers was replaced during the second half of the eighteenth century by stimulant therapy which in turn was partially abandoned in the early nineteenth century for the antiphlogistic approach.

From our own viewpoint, it would seem that none of our doctors could offer much objective help to the patient suffering from a "fever". Even in the special case of the bark for malaria, problems of purity, supply, and dosage undoubtedly mitigated against a consistent degree of successful therapeutic intervention. Over the long haul, therapy is more constant than theory, and the principal kinds of therapy outlined by Cullen had been available to the Hippocratics. In the short run, however, there are pronounced swings in therapeutic fashion. Why? No simple answer is possible, but a whole range of issues - doctor-patient relationships, professional hierarchies, the nature of medical "evidence" - must be taken into account. Viewed in this way, the history of therapeutics can become much more than a depressing account of repeated bleedings and purgings; it can become a way into the urgent professional and social realities of the medicine of any particular period. ${ }^{38}$

\footnotetext{
${ }^{37}$ Peter H. Niebyl, 'The English bloodletting revolution, or modern medicine before 1850', Bull. Hist. Med., 1977, 51: 464-483.

${ }^{38} \mathrm{E}$. H. Ackerknecht, Therapeutics from the primitives to the twentieth century, New York, Hafner, 1973.
} 